\title{
Retinotopic Organization of Human Visual Cortex Mapped with Positron-Emission Tomography
}

\author{
Peter T. Fox,,$^{1,2}$ Francis M. Miezin, ${ }^{3}$ John M. Allman, ${ }^{3}$ David C. Van Essen, ${ }^{3}$ and Marcus E. Raichle ${ }^{1,2,4}$ \\ Departments of 'Neurology and Neurosurgery (Neurology), and 'Radiology, Washington University School of Medicine, \\ and ${ }^{3}$ Division of Biology, California Institute of Technology, Pasadena, California 91125, and ${ }^{4} \mathrm{McDonnell}$ Center for \\ Studies of Higher Brain Function, Washington University School of Medicine, St. Louis, Missouri 63310
}

The retinotopic organization of primary visual cortex was mapped in normal human volunteers. Positron-emission tomographic measurements of regional cerebral blood flow were employed to detect focal functional brain activation. Oxygen-15-labeled water, delivered by intravenous bolus, was used as the blood flow tracer to allow multiple stimulated-state $(n=5)$ and control-state $(n=3)$ measurements to be acquired for each of 7 subjects. Responses were identified by applying a maximum-detection algorithm to subtraction-format images of the stimulus-induced change in cerebral blood flow. Response locales were described using a standardized system of stereotactic coordinates. Changes in stimulus location (macular, perimacular, peripheral, upper-field, lower-field) caused systematic, highly significant changes in response locale within visual cortex. Discrete extrastriate visual responses were also observed.

Positron-emission tomographic (PET; Raichle, 1983) measurements of cerebral blood flow (CBF) can be used for functional mapping in the normal human brain (Fox and Raichle, 1984, 1986; Fox et al., 1985a). Recently developed techniques for response detection and anatomical localization allow functional cortical mapping to a precision of a few millimeters (Fox et al., $1985 \mathrm{~b}, 1986)$. This suggests the possibility of extending to man the detailed knowledge of visual cortex that has been accumulated for nonhuman species (for recent reviews, see Van Essen, 1985; and Allman and McGuinness, 1986). As a first step in this endeavor, we have mapped the retinotopic organization of human visual cortex on the medial wall of the occipital lobe using PET measurements of CBF, and identified additional laterally situated extrastriate visual responses.

\section{Materials and Methods}

\section{Tomograph characteristics}

The PETT VI system was employed (Yamamoto et al., 1982). This tomograph simultaneously acquires 7 parallel slices with a center-tocenter, interslice distance of $14.4 \mathrm{~mm}$. All scans were performed in the low-resolution mode at an axial (in-plane) resolution of $13.9 \mathrm{~mm}$ full-

\footnotetext{
Received June 3, 1986; revised Aug. 25, 1986; accepted Sept. 13, 1986.

We thank Lennis Lich and Thomas Hurley for expert technical assistance and Thomas Videen for programming the computer-generated stimuli. This work was supported by NIH Grants NS-06833, HL-13851, NS-07025, NS-0094 (Teacher Investigator Development Award, to P.T.F.), EY03851, and RR-07003, and by a grant from the John Norris Curry Gordon and Jessie Kennicott Gordon Trust.

Correspondence should be addressed to Dr. Peter T. Fox, Division of Radiation Sciences, Campus Box 8131, Washington University School of Medicine, $660 \mathrm{~S}$. Euclid, St. Louis, MO 63110.

Copyright (c) 1987 Society for Neuroscience $0270-6474 / 87 / 030913-10 \$ 02.00 / 0$
}

width at half-maximum (FWHM) and a vertical (between-plane) resolution of $14.4 \mathrm{~mm}$ FWHM, as measured in the center of the field of view. Images were reconstructed by filtered back-projection to an image resolution of $18 \mathrm{~mm}$ FWHM (see "Localization versus resolution" in the Discussion for a treatment of image resolution). Numerical pixel size was $2.7 \mathrm{~mm}$.

\section{Subject preparation}

Subject preparation methods have been discussed extensively elsewhere (Fox and Raichle, 1984; Fox et al., 1985a) and will bc briefly summarized here. Seven normal human volunteers, 5 female and 2 male, ranging in age from 20 to 24 , were studied. Subjects were recruited by means of notices placed in nonpatient areas of the medical school complex and were predominantly medical and paramedical students, technicians, and medical professionals. Informed consent was obtained from each subject, following the guidelines of the Human Studies Committee and the Radioactive Drug Research Committee (Food and Drug Administration) of Washington University.

Head positions were adjusted using laser alignment beams until each head lay symmetrically about the midsagittal plane, and the planes of section included the region of primary interest, i.e., the occipital pole. The head was then immobilized within a closely fitted, thermally molded plastic facial mask made individually for each subject (Fox et al., 1985b). The mask extended vertically from the upper forehcad (hairlinc) to the tip of the nose and extended circumferentially to the posterior aspects of the mastoid bones. A wide field of view was provided by oval eye holes in the mask. After the mask cooled and became rigid (2-3 min), head alignment and planes of section were recorded with a lateral radiograph (Fox et al., 1985b). Venous and arterial catheters were placed in opposite arms.

\section{Tracer techniques}

Brain blood flow (BF) was measured using techniques fully described and validated elsewhere (Herscovitch et al., 1983; Raichle et al., 1983). Water labeled with oxygen-1 5 (half-life, $123 \mathrm{sec}$ ) served as a freely diffusible $B F$ tracer and was administered as an intravenous bolus of $8-12 \mathrm{ml}$ of saline containing $50-80 \mathrm{mCi}$. A 40 sec scan acquisition was initiated when the tracer bolus entered the brain, as indicated by an abrupt rise in the coincidence-counting rate of the tomograph. Arterial blood samples were obtained every 3-5 sec from isotope injection until scan completion to provide the arterial time-activity function. Calculation of brain $\mathrm{BF}$ was based upon the principles of inert gas exchange, as adapted for PET by Raichle and colleagues (1983), using the PET image of radiotracer distribution and the arterial time-activity function. Each subject underwent 8 independent PET measurements of brain BF during an 80-90 min scanning session. A $10 \mathrm{~min}$ interscan interval was sufficient for isotope decay (5 half-lives), and to reestablish resting-state levels of regional BF within activated areas (Fox and Raichle, 1984).

\section{Stimulus conditions}

Equipment. Stimuli were presented on a color monitor (HX12; Princeton-Graphics, Princeton, NJ) using a commercial image-display system (RM-9400; Ramtek, Santa Clara, CA). The monitor was suspended on an adjustable gantry with the screen surface 12 in. from the anterior pole of the eye and perpendicular to the line of sight. Uncontrolled 
A
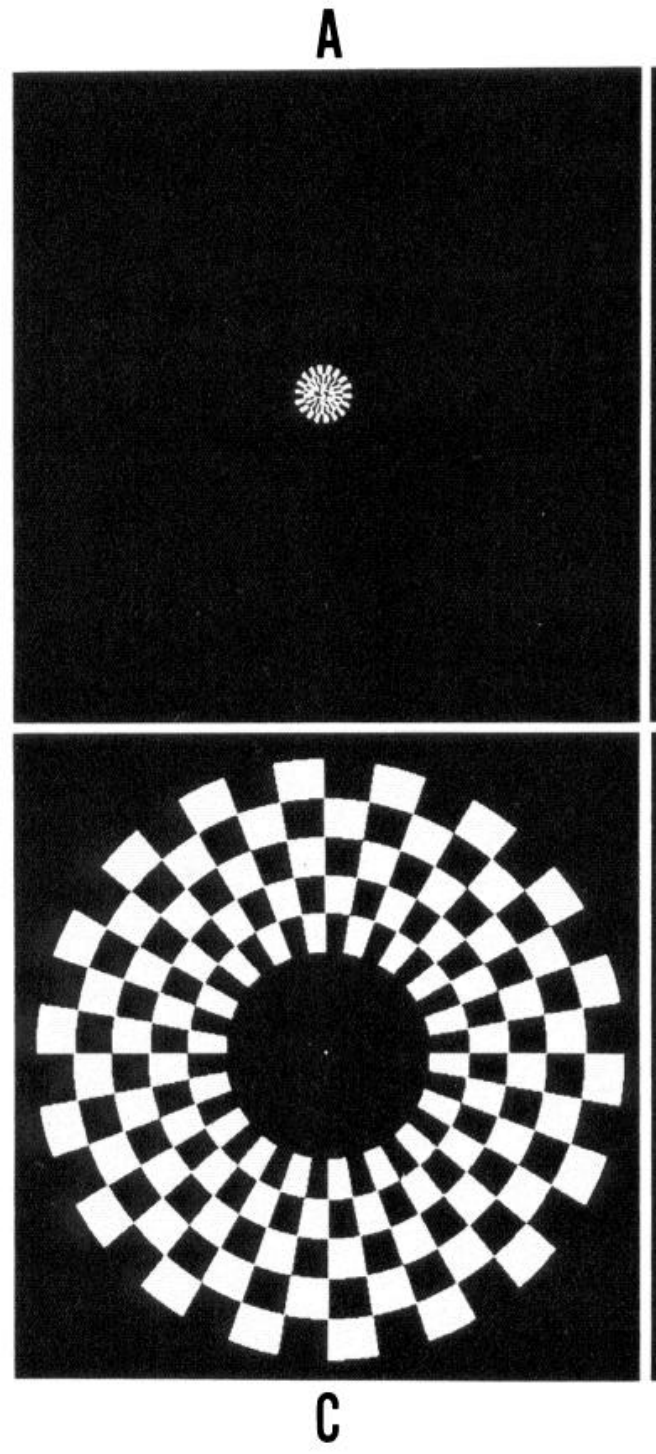

B

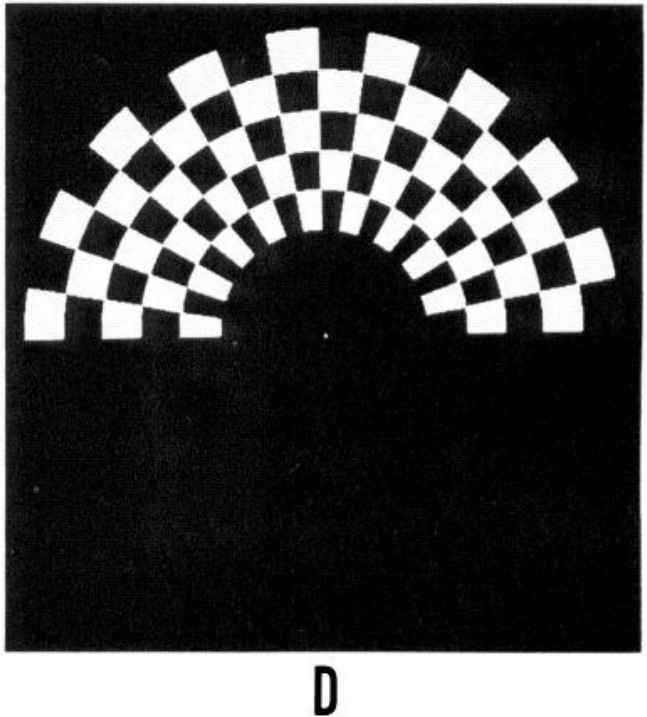

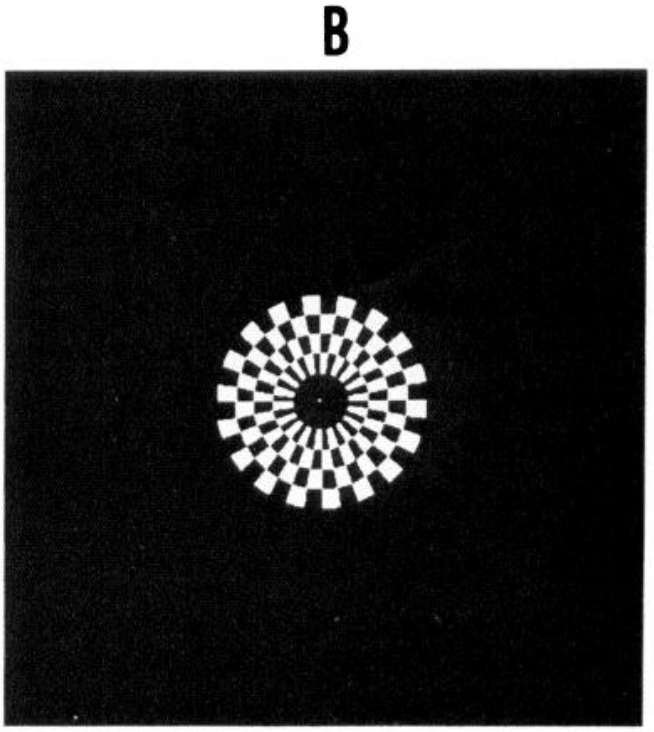

Figure 1. A, Macular annulus extended radially from $0.1^{\circ}$ to $1.5^{\circ}$, with a check size of $0.5^{\circ}$. B , Perimacular to $5.5^{\circ}$, with a check radius of $1.0^{\circ}$. C, Peripheral annulus extended radially from $5.5^{\circ}$ to $15.5^{\circ}$, with a check radius of $2.0^{\circ}$. D , Hemiannulus positioned on either side of the horizontal meridian and extended radially from $5.5^{\circ}$ to $15.5^{\circ}$, with a check radius of $2.0^{\circ}$. All stimuli were red-on-black checkerboards, alternating colors at $10 \mathrm{~Hz}$ to maximize response intensity (Fox and Raichle, 1984, 1985). Angular check subtense was $10.0^{\circ}$ for all conditions. annulus extended radially from $1.5^{\circ}$

visual stimulation was eliminated by surrounding the subject with dense fabric drapes and dimming room lights during stimulus presentation.

Instructions. The subject's task, for all trials, was to maintain fixation on a cross-hair in the center of the screen. Each trial began $15 \mathrm{sec}$ before isotope injection, when the instruction to open the eyes was given. Total task performance time was $50-70 \mathrm{sec}$. Fixation was maintained during these brief trials, as verified by electrooculographic recordings (4 of 7 subjects) and by the subjects' own reports. Between trials, the subjects lay quietly with their eyes closed, as was repeatedly confirmed by direct observation.

Stimulus patterns. Each subject underwent 8 trials, i.e., 8 PET scans of brain $\mathrm{BF}$, during a single scanning session. A centrally placed crosshair $\left(0.2^{\circ}\right.$ span $)$ served as the fixation point and appeared during all trials. During the 3 control trials $(2,5$, and 8$)$, only the fixation point was viewed. During the 5 stimulated-state trials, the subjects viewed restricted-field stimuli consisting of red-and-black checkered annuli or annular segments centered about the fixation point (Fig. 1). The circumferential check size was fixed at $10^{\circ}$ (polar angle; 36 checks/full circle). Radial check size varied with eccentricity to emulate the magnification factor of striate cortex (Daniel and Whitteridge, 1961; Cowey and Rolls, 1974; Rovamo and Virsu, 1979). Checks were alternated in color at $10 \mathrm{~Hz}$ to maximize the induced $\mathrm{BF}$ responses, on the basis of the known frequency dependence of BF in visual cortex (Fox and Raichle, 1984, 1985)

The control state, against which all other responses were tested, consisted of viewing the fixation cross-hair alone. The macular stimulus was an annulus extending radially from 0.1 to $1.5^{\circ}$, with a radial check size of $0.5^{\circ}$. The perimacular stimulus was an annulus extending from $1.5^{\circ}$ to $5.5^{\circ}$, with a radial check size of $1.0^{\circ}$. The peripheral stimulus was an annulus extending from $5.5^{\circ}$ to $15.5^{\circ}$, with a radial check size of $2.0^{\circ}$. Upper-field and lower-field stimuli were hemiannuli $(n=3)$ or quarter-annuli $(n=1)$ bisected by the vertical meridian and extending radially from $5.5^{\circ}$ to $15.5^{\circ}$, with a radial check size of $2.0^{\circ}$. The order of presentation was randomized across subjects.

\section{Data analysis}

Global cerebral blood flow. Global cerebral blood flow (gCBF) was determined using a standardized, mean-regional method (Perlmutter et al., 1985). This method uses a stereotactic localization procedure (Fox et al., 1985b; see also below) to identify 21 representative brain regions in each hemisphere. The mean value from 42 regions (both hemispheres) is the $\mathrm{gCBF}$ for each subject.

Regional cerebral blood flow. The primary intent of this study was to locate and quantitate changes in regional cerebral blood flow (rCBF) induced by restricted-field visual stimuli. To prevent confounding taskinduced, focal $\mathrm{CBF}$ changes with fluctuations affecting the entire brain (e.g., due to changes in arterial $\mathrm{PCO}_{2}$ ), $\mathrm{rCBF}$ changes were analyzed after linear normalization that negated the effects of $\mathrm{gCBF}$ fluctuation, both inter- and intrasubject. This consisted of multiplying every pixel of each CBF scan by a correction factor, calculated as the mean normal $\mathrm{gCBF}$ of this laboratory $[50 \mathrm{ml} /(100 \mathrm{gm} \times \mathrm{min})]$ divided by the scan gCBF, before making rCBF comparisons (Fox et al., 1985a).

A series of 8 sequential BF measurements lasted $80-90 \mathrm{~min}$. During this period, small $(1-2 \mathrm{~mm})$ head movements occasionally occurred, particularly translations along the vertical axis. Accurate topographic mapping necessarily depends upon a close anatomical correspondence 


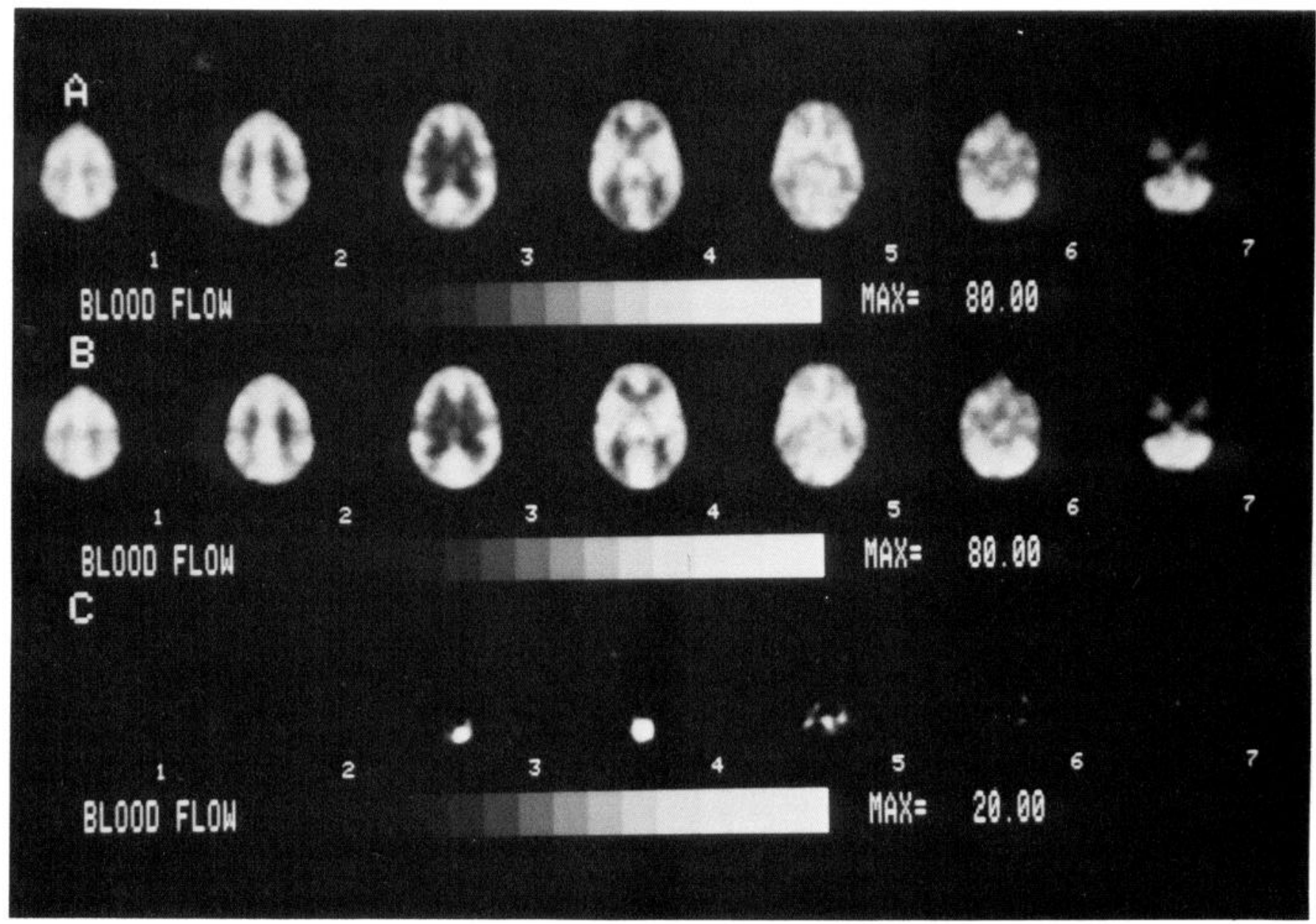

Figure 2. Seven slice horizontal images from a single subject's scanning session. $A$, Resting-state image of cerebral blood flow (CBF). B, CBF image acquired while viewing the peripheral annulus $\left(5.5^{\circ}-15.5^{\circ}\right)$. $C$, Image of the absolute change in CBF (CBF $\left.\Delta\right)$ induced by peripheral visual stimulation, arrived at by subtracting image $A$ from image $B(C=B-A)$. CBF responses usually extended across $2-3$ contiguous sections, as seen here (sections 3-5). For this reason, response location was identified using interslice interpolation and a computerized search routine (see Region of interest placement). This identified the brain volume $\left(8 \mathrm{~cm}^{3}\right)$ having the greatest increase in CBF during the stimulus.

between the stimulated and control measurements. To assure anatomical correspondence between each stimulus trial and some control trial, the second, fifth, and eighth measurements in a series were used as controls. Anatomical correspondence was determined by visual inspection in a $\mathrm{rCBF}$ percent change $(\mathrm{rCBF} \% \Delta)$ image format, as described elsewhere (Fox and Raichle, 1984). This data format is particularly sensitive to head movements, which appear as arcs or rings of large $\mathrm{rCBF} \% \Delta$ at brain-nonbrain boundaries. Control conditions were graded for anatomical fit in relation to each stimulus trial using $\mathrm{rCBF} \% \Delta$ images (controls 1-3, from best to worst; see Table 4). All topographic analysis was performed in relation to the control trial with the best anatomical fit to the stimulus trial (control 1). Analysis of the significance of the rCBF responses, however, included all 3 control groups, as this procedure was the most rigorous.

Region of interest placement. Brain regions responsive to visual stimulation were determined as follows: Each stimulated-state measurement was transformed into a measurement of stimulation-induced change in $\mathrm{rCBF}(\mathrm{rCBF} \Delta$ ) (Fig. 2). This was done by a pixel-for-pixel subtraction of the corresponding fixation-point-only control scan from the stimulated-state scan after gCBF normalization, as described above. The resulting 7 slice matrix of $\mathrm{rCBF} \Delta$ then underwent liner interpolation in the vertical (interslice) axis to create a 3-dimensional matrix of rCBF $\Delta$ values with nearly uniform pixel size (about $3 \mathrm{~mm}$ ) in all directions. This interpolated rCBF $\Delta$ matrix was then automatically analyzed by a computerized-search algorithm using a 3-dimensional region of interest with 7 pixels (about $20 \mathrm{~mm}$ ) on each side; all possible region of interest locations were assessed. Reported rCBF values (see Table 5) were the mean values of the $7 \times 7 \times 7$ pixel volumes circumscribing the max- imum rCBF $\Delta$ occurring within each subject's brain. Response location coordinates (see Tables 2 and 4) were those of the geometric centers of the same volumes.

Anatomical localization. All correlations between PET images and anatomical structures were made using a stereotactic method of anatomical localization developed and validated within this laboratory for use with PET (Fox et al., 1985b). This method translated tomographic coordinates into proportionately measured stereotactic coordinates relating to the line between the anterior and posterior commissures (ACPC line or bicommissural line) (Talairach et al., 1967).

Retinotopy was mapped by changes in the locations of the response foci along the anterior-posterior $(y)$ and superior-inferior $(z)$ axes (see Tables 2, 4; Figs. 4, 5). Medial-lateral ( $x$ axis) coordinates are not reported because the close apposition of the medial surfaces of the cerebral hemispheres often prevented the establishment of a discrete response focus within each hemisphere. Consistent discrimination between left- and right-hemispheric responses is best accomplished using hemifield stimulus presentations. Herein, however, stimuli were presented bilaterally to increase the amount of cortex stimulated and the intensity of the measured rCBF response (Fox et al., 1985a).

Statistical methods. Comparisons between 2 conditions were made with a $t$ test. Comparisons among more than 2 conditions were made using a 1-way, repeated-measures analysis of variance (ANOVA). For either test, the significance level was set at 0.05 divided by the number of independent tests performed (Bonferroni procedure; Cupples et al., 1984). For statistically significant ANOVAs, post hoc analysis was performed with a repeated-measures Newman-Keuls procedure, which included a correction for the number of intercomparisons (Zar, 1974). 


\begin{tabular}{lll}
\hline Table 1. Global cerebral blood flow & \\
& $\begin{array}{l}\text { Control state mean } \\
\text { (SD, range) } \\
(n=3)\end{array}$ & $\begin{array}{l}\text { Stimulated-state } \\
\text { mean (SD, range) } \\
(n=5)\end{array}$ \\
Subject & $47(4.1,41-51)$ & $50(5.9,43-58)$ \\
\hline 1 & $45(1.9,43-48)$ & $44(4.9,41-53)$ \\
2 & $54(2.3,52-57)$ & $52(4.3,46-59)$ \\
3 & $52(4.2,46-57)$ & $54(9.1,45-71)$ \\
4 & $49(2.8,45-52)$ & $47(2.3,45-51)$ \\
5 & $51(3.0,47-54)$ & $48(4.9,44-58)$ \\
6 & $56(5.8,48-61)$ & $60(6.0,50-67)$ \\
7 & $51(3.4)$ & $51(5.3)$ \\
Mean & $(n=21)$ & $(n=35)$ \\
\multirow{2}{*}{ Combined } & $51^{*}(4.9,43-61)$ & $51^{*}(7.4,41-71)$ \\
\hline
\end{tabular}

Cerebral blood flow was measured in units of $\mathrm{ml} /(100 \mathrm{gm} \times \mathrm{min})$. There was no difference between the means for the 2 states; $p>0.8$ by $t$ test $\left(^{*}\right)$.

\section{Results}

\section{Global cerebral blood flow}

The mean gCBF for all 56 scans performed on the 7 subjects was $51 \mathrm{ml} /(100 \mathrm{gm} \times \mathrm{min}) \pm 5.6(\mathrm{SD})$. Minor fluctuations in gCBF occurred between successive scans of the same individual, as well as between individuals. gCBF was not, however, significantly affected by test conditions: none of the 5 stimulus trials showed a significant difference in $\mathrm{gCBF}$ from any of the 3 control trials (independent ANOVAs; $p>0.5$ ). Nor did a pooled comparison of all stimulated trials with all control trials show a significant difference in mean gCBF ( $t$ test; $p>0.8$; Table 1 ).

The invariance of gCBF during intense, but focal, brain activation agreed with our prior experience (Fox and Raichle, 1984; Fox et al., 1985a) and corroborated the original observation of Sokoloff and colleagues (1955) that focal brain activity (mental arithmetic) did not measurably affect gCBF. The excellent intrasubject reproducibility of the current measurements (Table 1) further strengthened this observation.

\section{Regional cerebral blood flow}

Patterns of activation. Visual inspection of every scan in the $\mathrm{rCBF} \Delta$ format (see Materials and Methods) showed that all 5 restricted-field stimuli (see Fig. 1) induced intense, focal increases in rCBF in the medial-posterior regions of the occipital lobe in every subject (see Fig. 2). These primary responses typically extended across 2-3 adjacent image planes, i.e., had an apparent vertical extent of about $1.4-2.8 \mathrm{~cm}$ (Fig. 2). Often the dorsal and ventral poles of the responses lay further from the midsagittal plane than did their center portions. In every instance, a retinotopic organization of the primary responses was readily apparent, on simple visual inspection, in the anteriorposterior axis, the vertical axis, or both. We consider that these primary responses originated in large part from striate cortex, but include a significant extrastriate (V2 or Brodmann's area 18) component for reasons elaborated in the Discussion.

Additional extrastriate visual responses were seen in at least 1 stimulus trial of 5 of the 7 subjects. These responses typically took the form of discrete, but less intense, foci of rCBF increase, lying dorso-lateral and/or ventro-lateral to the more intense medial responses (Fig. 3). In this report, formal analysis is restricted to the primary (V1/V2) responses.

Response location. In every trial the maximum $\mathrm{rCBF}$ increase
Table 2. Retinotopy by stimulus eccentricity expressed in stereotactic coordinates

\begin{tabular}{llll} 
& Macula & Perimacula & Periphery \\
\hline Degrees & $0.1-1.5$ & $1.5-5.5$ & $5.5-15.5$ \\
$n$ & 5 & 6 & 6
\end{tabular}

$\begin{array}{lll} & \text { Anteroposterior axis }(\mathrm{cm}) & \\ \text { Mean (SD) } & -6.86(0.13) \quad-6.29(0.09) & -5.96(0.07) \\ \text { Statistical } & \text { ANOVA: } F=42, p<0.00001 & \\ \text { Analysis } & \text { Newman-Keuls: macula }<\text { perimacula }<\text { periphery; } \\ & p<0.01 \text { for all inequalities } & \\ & \quad \text { Vertical axis }(\mathrm{cm}) \\ \text { Mean (SD) } & -0.50(0.36) \quad-0.12(0.32) & 0.64(0.42) \\ \text { Statistical } & \text { ANOVA: } F=90, p<0.00001 & \\ \text { Analysis } & \text { Newman-Keuls: macula }<\text { perimacula }<\text { periphery; } \\ & p<0.01 \text { for all inequalities }\end{array}$
All stimuli were full annuli with a central fixation point (see Fig. 1). Response
locations were determined by a maximum-detection algorithm that identified the brain volume $(1.9 \mathrm{~cm}$ on each side) having the greatest absolute change in $\mathrm{rCBF}$ during each stimulus condition. Stereotactic coordinates were determined as previously described (Fox et al., 1985b). A significance level of 0.025 was set to correct for the number of ANOVAs performed (0.05/2; Bonferroni procedure) (Cupples et al., 1984).

lay on the medial surface of the occipital lobe, at the approximate level of the calcarine fissure. Response location varied with the portion of the retina stimulated in a direct and highly significant manner (Tables 2, 4; Figs. 4, 5).

Macular responses, as measured within the $7 \times 7 \times 7$ pixel region of interest, lay approximately $1 \mathrm{~cm}$ anterior to the occipital poles, as was expected from a stimulus with a mean eccentricity of $0.7^{\circ}$. The zone of increased CBF, however, extended to the occipital pole in all subjects, as the stimulus field extended to within $0.1^{\circ}$ of the fixation point. A progressive increase of mean stimulus eccentricity from $0.7^{\circ}$ (macula) to $3.5^{\circ}$ (perimacula) to $10.5^{\circ}$ (periphery) was mirrored by a consistent anterior and superior movement of the $\mathrm{CCBF}$ response (Table 2, Figs. 4, 5). Note that mapping at the millimeter level (3-8 $\mathrm{mm}$; Table 2) was accomplished with an image resolution of 18 mm FWHM (see "Localization versus resolution" below).

The magnification factor has been defined as the linear extent of striate cortex to which each degree of the retinal visual field projects (Daniel and Whitteridge, 1961; Cowey and Rolls, 1974). Variations in response location with stimulus eccentricity (Table 2) allowed a lower boundary for the magnification factor in human striate cortex to be calculated for 3 eccentricities (Table

Table 3. Magnification factor in human striate cortex

\begin{tabular}{llll} 
Comparison & $\begin{array}{l}\text { Macula } \\
\text { to peri- } \\
\text { macula }\end{array}$ & $\begin{array}{l}\text { Macula } \\
\text { to peri- } \\
\text { phery }\end{array}$ & $\begin{array}{l}\text { Peri- } \\
\text { macula } \\
\text { to peri- } \\
\text { phery }\end{array}$ \\
\hline Rcsponse shift $(\mathrm{mm})$ & 9.4 & 15.6 & 6.6 \\
Stimulus shift $(\mathrm{deg})$ & 2.8 & 9.8 & 7.0 \\
Mean eccentricity $(\mathrm{deg})$ & 2.1 & 5.6 & 7.0 \\
Magnification factor $(\mathrm{mm} / \mathrm{deg})$ & 3.4 & 1.6 & 0.9
\end{tabular}

These values were calculated from the mean eccentricity of each stimulus pattern (macula $=0.7$, perimacula $=3.5$, periphery $=10.5^{\circ}$ ) and the mean response locale for that stimulus from 6 subjects (Table 2). 

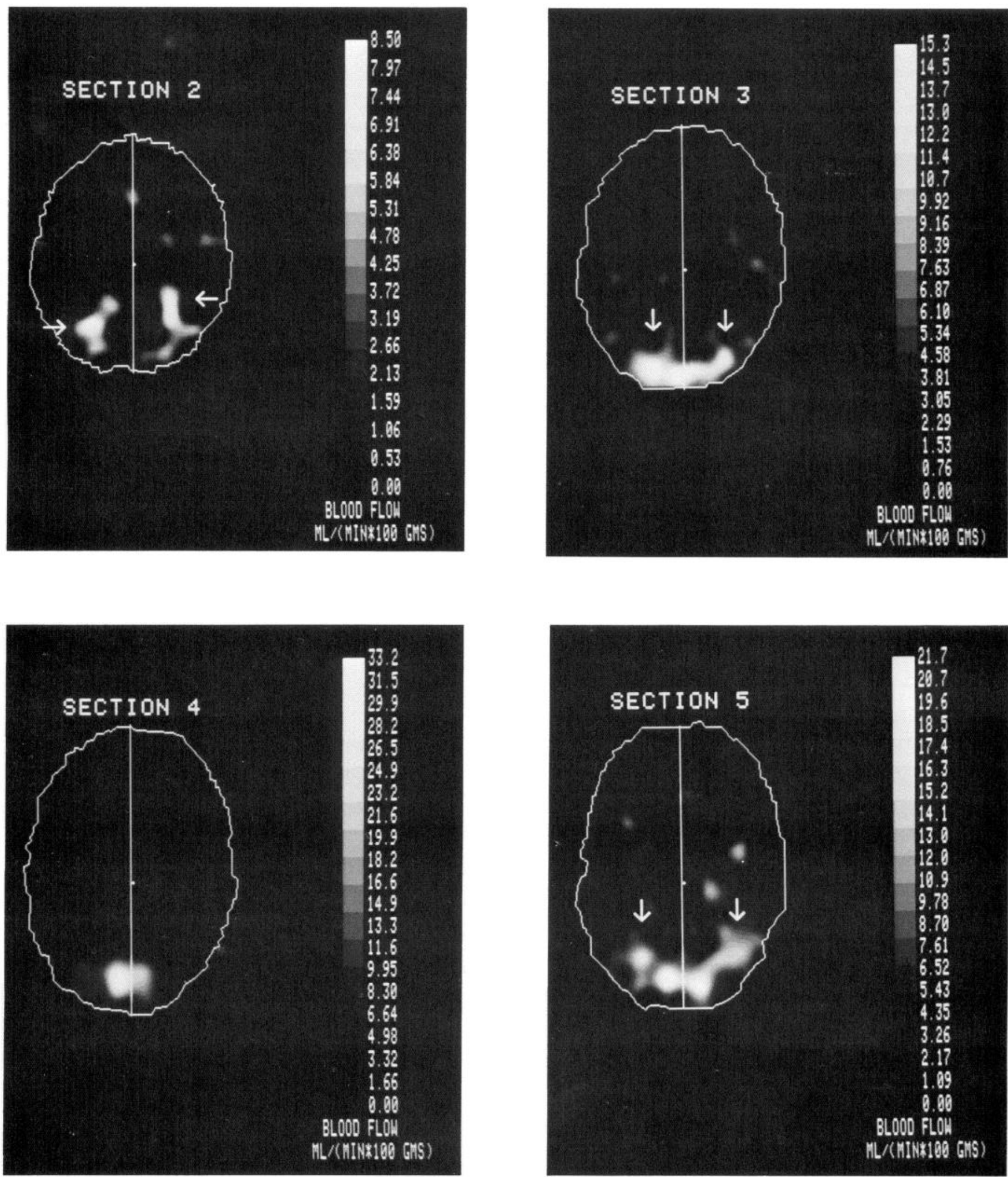

Figure 3. Extrastriate visual area responses (shown here) were elicited in many stimulus trials. These typically appeared as discrete foci of increased blood flow lying dorsolateral (arrows, sections 2 and 3) and ventrolateral (arrows, section 5) to the medially situated primary visual responses (sections 3 and 4). These 4 sections are simultaneously acquired horizontal-plane images of the increase in blood flow induced by peripheral-field $\left(5.5^{\circ}-15.5^{\circ}\right)$ visual stimulation. Sections progress from superior (section 2) to inferior (section 5). Brain left is to the reader's left; anterior is at the top. Note that the scales are not identical for each section. Each scale was allowed to seek the maximum value within the section to provide maximum image detail. The primary visual (V1) response is centered at section 4 , as indicated by the peak intensity [33 $\mathrm{ml} /(100 \mathrm{gm} \times \mathrm{min})]$ for that section. 

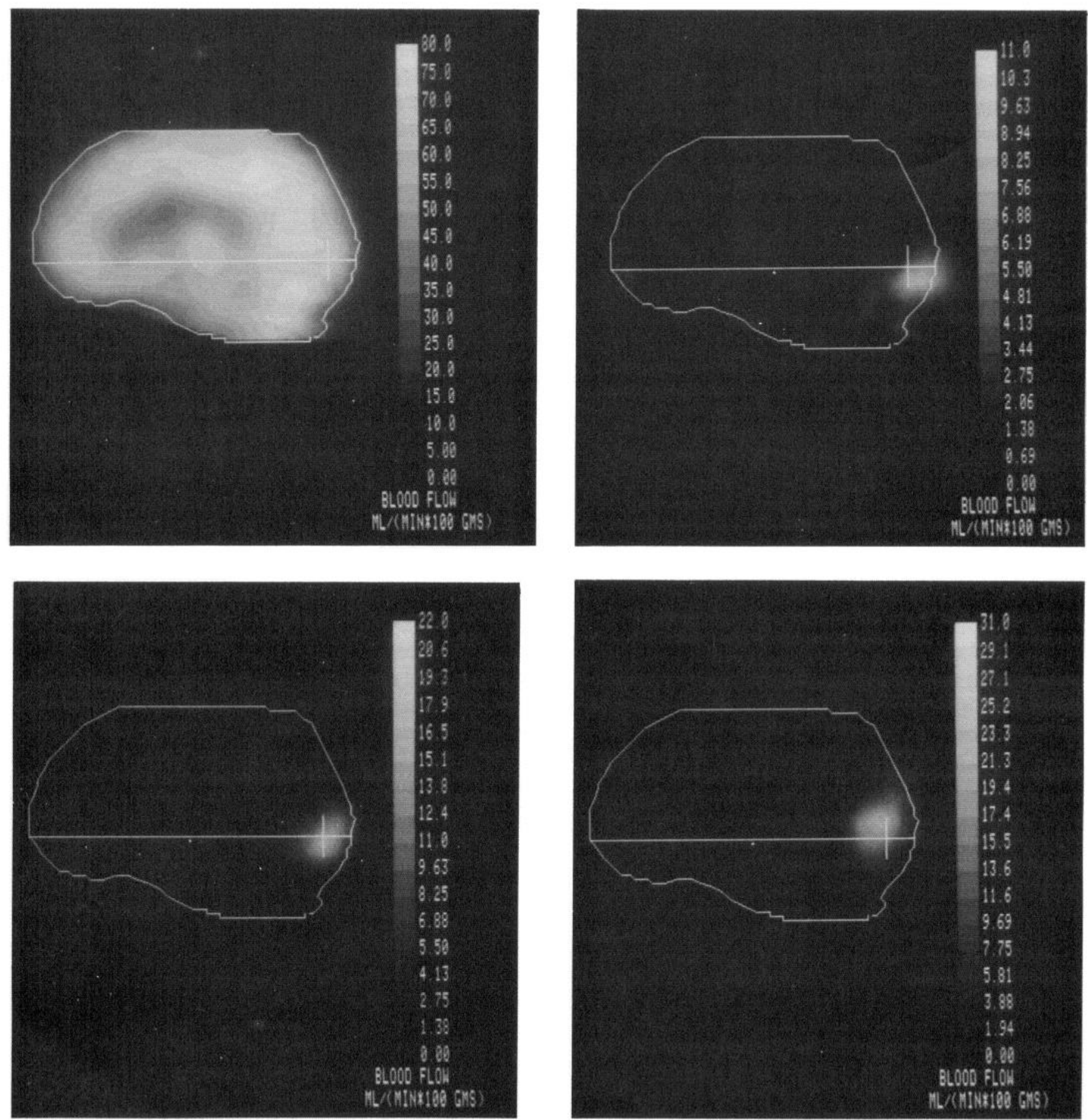

Figure 4. Upper left, Resting-state image of cerebral blood flow (CBF). Upper right, Macular response focus in a subtraction-image format. The response lies mostly posterior and inferior, at the occipital pole. Lower left, Perimacular response focus in subtraction-image format, intermediate in location between the macular and peripheral responses. Lower right, Peripheral response focus in subtraction-image format, anterior and superior to the 2 other responses. All images are midsagittal sections formed by summing the images of all 6 subjects within the standardized stereotactic coordinate space (Fox et al., 1985b). Anterior is to the left. The brain boundary was obtained from image $A$ and is positioned identically in all 4 images. Horizontal lines represent the bicommissural line. Vertical lines are $2.0 \mathrm{~cm}$ in length and transect the bicommissural line $6.2 \mathrm{~cm}$ posterior to its center. The effect of stimulus eccentricity on response locale was highly significant (Table 2).

3). This was a lower boundary because cortical infolding and curvature of the calcarine fissure could not be compensated for with this measurement technique.

Retinotopy was also demonstrated using superior and inferior hemifield stimuli (Table 4, Fig. 5). Superior-field stimuli induced responses inferior and anterior to the full-field responses. Inferior-field stimuli responses were superior and posterior to full-field responses. 
Table 4. Superior-field-inferior-field retinotopy expressed in stereotactic coordinates

\begin{tabular}{|c|c|c|}
\hline $\begin{array}{l}\text { Stimulus field } \\
(n)\end{array}$ & $\begin{array}{l}\text { Upper field } \\
\text { (4) }\end{array}$ & $\begin{array}{l}\text { Lower field } \\
\text { (4) }\end{array}$ \\
\hline \multicolumn{3}{|c|}{ Anteroposterior axis $(\mathrm{cm})$} \\
\hline Mean (SD) & $\begin{array}{r}-5.42^{*}(0.43) \\
\text { Vertical axi }\end{array}$ & $-6.37^{*}(0.57)$ \\
\hline Mean (SD) & $0.66^{* *}(0.70)$ & $1.66^{* *}(0.58)$ \\
\hline
\end{tabular}

Stimuli were either hemiannuli $(n=3)$ or quarter-annuli $(n=1)$ bisected by the vertical-meridian. Stimuli extended radially from $5.5^{\circ}-15.5^{\circ}$ (see Fig. 1). Response locations were determined by a maximum-detection algorithm that identified the brain volume (1.9 cm on each side) having the greatest absolute change in rCBF during each stimulus condition. Stereotactic coordinates were determined as previously described (Fox et al., 1985b). The means for each field were compared separately for each axis (paired $t$ test): ${ }^{*} p<0.01 ; * * p<0.001$. Significance level was set at 0.025 to correct for the number of comparisons $(0.05 / 2$; Bonferroni procedure) (Cupples et al., 1984).

Response magnitude. The significance of these focal increases in CBF was tested against each of the 3 control conditions. All 5 stimulus conditions produced significant local increases in relation to every control state, while none of the control states showed significant local variations (Table 5). The greatest rCBF variation between any of the 3 control states for any of the 5 regions was $1 \mathrm{ml} /(100 \mathrm{gm} \times \mathrm{min})$, while stimulus-induced mean rCBF changes ranged from 7 to $18 \mathrm{ml} /(100 \mathrm{gm} \times \mathrm{min})(12 \mathrm{ml}$, mean). Thus, the focal CBF responses induced by these restricted-field stimuli were consistently well in excess of any non-taskrelated fluctuations, either technical or physiological, in measured CBF.

\section{Discussion}

Cortical retinotopy. The general arrangement of retinal projections to striate cortex is well understood; that is, central retina projects caudally, in the vicinity of the accipital pole, while peripheral retina projects rostrally; superior retina projects above the calcarine fissure and inferior retina projects beneath the fissure. This broad outline has been drawn from numerous case reports of missile injuries (Holmes and Lister, 1916; Holmes, 1918; Spalding, 1952; Teuber et al., 1960) and infarctions (McAuley and Ross-Russell, 1979; Spector et al., 1981) of the occipital lobe. Yet induction from pathophysiology has inherent limitations. One of these has been that lesions tend to be stereotyped by the pathological processes themselves. For example,

Figure 5. Midsagittal stereotactic plots of the retinotopic organization of human striate cortex. The effects of stimulus field on response locale are highly significant (Tables 2 and 4). Upper, Response locale varied systematically as a function of stimulus eccentricity using macular, perimacular, and peripheral annulus stimuli, which extended radially from $0.1^{\circ}$ to $1.5^{\circ}, 1.5^{\circ}$ to $5.5^{\circ}$, and $5.5^{\circ}$ to $15.5^{\circ}$, respectively. In all instances $(n=6)$, highly consistent retinotopy was observed. Middle, Superiorinferior retinotopy was also demonstrated using a hemiannulus $(n=3)$ or a quarter-annulus $(n=1)$ bisected by the vertical-meridian and alternately placed in the upper and lower fields. The outlying pair of responses (filled symbols) indicates responses to the quarter-annulus. Lower, Mean coordinates ( \pm 1 SD along each axis) are shown for each stimulus field. Locations plotted are those of the geometric center of the brain volume $\left(8 \mathrm{~cm}^{3}\right)$ undergoing the greatest absolute change in cerebral blood flow during that stimulus condition. For each subject, all stimulated-state and resting-state measurements were made during a single, 8-scan session ( $80-90 \mathrm{~min}$ ). The stereotactic localization procedure has been described previously (Fox et al., 1985b).

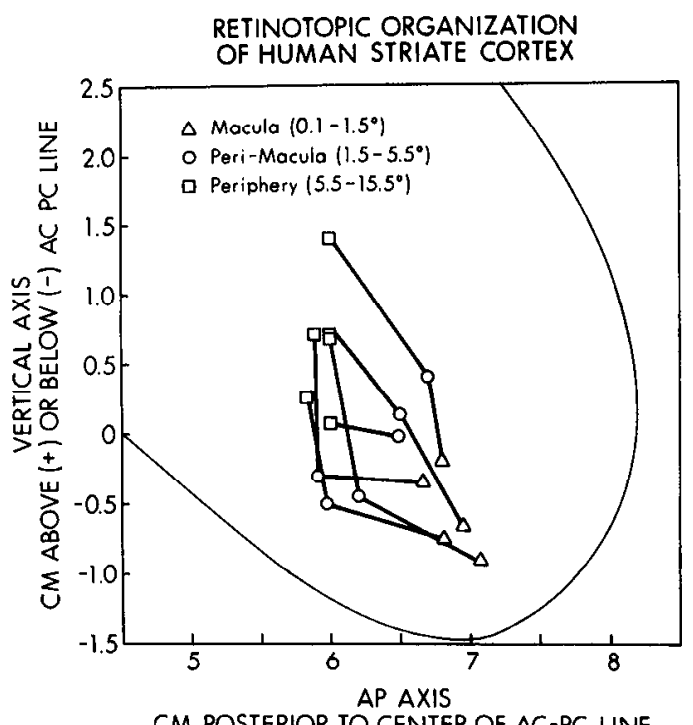

CM POSTERIOR TO CENTER OF AC-PC LINE

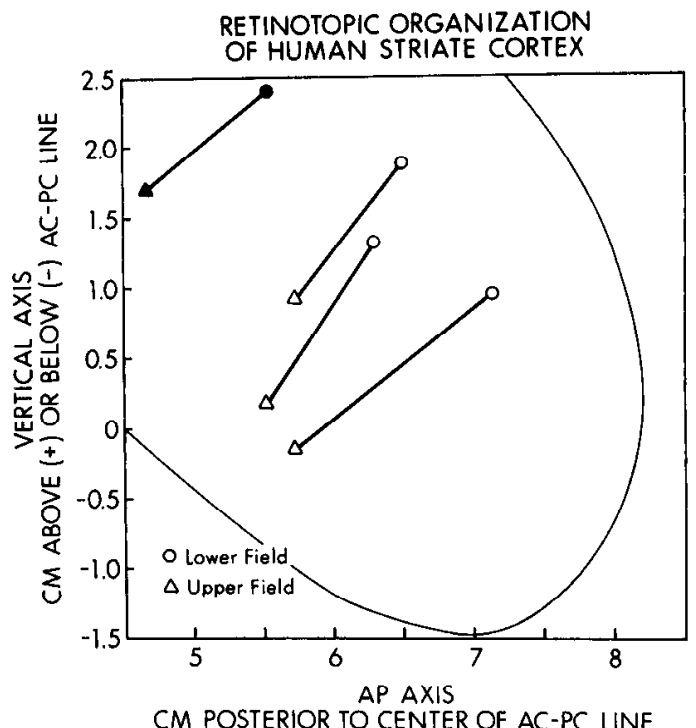

CM POSTERIOR TO CENTER OF AC-PC LINE

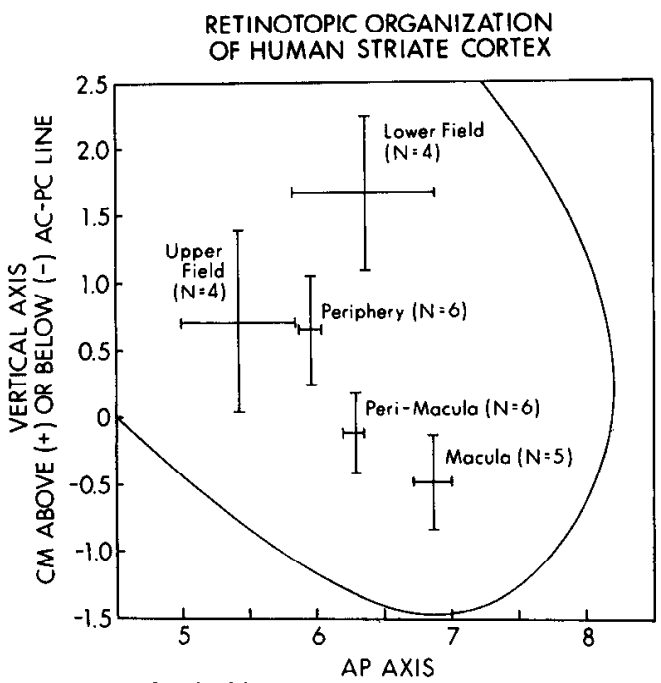

CM POSTERIOR TO CENTER OF AC-PC LINE 


\begin{tabular}{|c|c|c|c|c|c|}
\hline \multirow{2}{*}{$\begin{array}{l}\text { Region } \\
(n)\end{array}$} & \multirow{2}{*}{$\begin{array}{l}\text { Stimulus } \\
\text { means }\end{array}$} & \multicolumn{3}{|c|}{ Control means } & \multirow[b]{2}{*}{ Statistical-analysis } \\
\hline & & 1 & 2 & 3 & \\
\hline Macula (5) & 53 & 46 & 46 & 46 & $\begin{array}{l}\text { ANOVA: } F=101^{* *} \\
\text { N-K: } \mathrm{ST}>\mathrm{Cl}=\mathrm{C} 3=\mathrm{C} 2^{*}\end{array}$ \\
\hline Perimacula (6) & 68 & 55 & 56 & 56 & $\begin{array}{l}\text { ANOVA: } F=83^{* *} \\
\text { N-K: } \mathrm{ST}>\mathrm{C} 3=\mathrm{C} 2=\mathrm{C} 1^{*}\end{array}$ \\
\hline Periphery (6) & 77 & 60 & 60 & 61 & $\begin{array}{l}\text { ANOVA: } F=229 \\
\text { N-K: } \mathrm{ST}>\mathrm{C} 3=\mathrm{C} 1=\mathrm{C} 2 *\end{array}$ \\
\hline Upper field (4) & 69 & 60 & 61 & 61 & $\begin{array}{l}\text { ANOVA: } F=19^{* * *} \\
\text { N-K: ST }>C 3=C 2=C 1^{*}\end{array}$ \\
\hline Lower field (4) & 61 & 51 & 52 & 52 & $\begin{array}{l}\text { ANOVA: } F=36^{* * *} \\
\text { N-K: } S T>C 2=\mathrm{C} 3=\mathrm{Cl}^{*}\end{array}$ \\
\hline
\end{tabular}

Control conditions were ranked by anatomical fit to the stimulus condition from best (C1) to worst (C3) (see Data analysis). Regions of interest were established by a maximum-detection algorithm that determined the brain volume ( $1.9 \mathrm{~cm}$ on each side) having the greatest absolute change in cerebral blood flow (CBF) during the stimulus condition, in relation to control 1. CBF values were determined after normalization for fluctuations in whole brain blood flow (see Data analysis and Fox et al., 1985a). CBF was measured in units of $\mathrm{ml} /(100 \mathrm{gm} \times \mathrm{min})$. For each region, CBF values were compared across conditions by ANOVA, with a minimum significance level set at 0.01 to correct for the number of regions tested (0.05/5; Bonferroni procedure) (Cupples et al., 1984). As significant variation by condition was indicated by ANOVA $\left({ }^{* *} p<0.0000005 ;{ }^{* * *} p<0.0005\right)$ within each region of interest, Newman-Keuls (N-K) multiple-range testing was performed in each instance. ${ }^{*}$ A significance level of $p<0.001$ for all differences and of $p>0.2$ for all identities.

reports of isolated rostral-striate lesions are rare, as missiles must penetrate either caudal cortex or the optic radiations to reach rostral cortex (Holmes and Lister, 1916; Holmes, 1918; Spalding, 1952; Teuber et al., 1960). Similarly, patients with wounds transecting the inferior occipital lobe rarely survive. Another critical shortcoming has been the means by which lesion anatomy has been determined and described. Missile lesion studies have relied on entrance and exit wounds in estimating the intracranial trajectory and thereby the location and extent of striate damage. More recent studies have employed anatomical imaging [x-ray computed tomography (CT)] (McAuley and Ross-Russell, 1979; Spector et al., 1981) but have lacked a standardized, validated method of determining cortical anatomy within the CT image (Fox et al., 1985b). Other problems have included the difficulty of determining whether lesions involve cortex only or both cortex and white matter, the lack of postmortem confirmation of presumed lesion locale, and the gross extent of many of the reported lesions, which hindered precise mapping. Lesion-deficit correlations, therefore, have provided a general schema of striate organization, but not a quantitative description of retinal-cortical projection topography.

The first quantitative descriptions of cortical retinotopy came from attempts to develop a visual prosthesis for the blind (Brindley and Lewin, 1968; Brindley et al., 1972; Brindley, 1973; Dobelle and Mladejovsky, 1974; Stensaas et al., 1974). The visual-field locale of the visual illusions (phosphenes) induced by cortical electrical stimulation varies with the placement of a stimulating electrode, allowing the cortical projection zones of the retina to be mapped. Surprisingly, phosphene maps have proven "very irregular" (Brindley and Lewin, 1968; Brindley et al., 1972; Brindley, 1973; Dobelle and Mladejovsky, 1974), conforming only "roughly" to the expected arrangement of striate retinotopy. While Brindley was led to believe that the retinal projections to striate cortex were discontinuous and irregular (Brindley et al., 1972; Brindley, 1973), Dobelle and Mladejovsky (1974) discredited this conclusion and detailed the imprecisions inherent in this technique for topographic mapping. Thus, "Pre- cise mapping is quite difficult to accomplish in the operating room. Phosphenes move with eye position, and are frequently too close together to be resolved due to inaccuracies in pointing" (Dobelle and Mladejovsky, 1974). Seen in this context, the regularity and consistency of our data support the view that these irregularities were technical rather than physiological. This is also supported by the exquisite precision of the retinotopic projections to primary visual cortex that have been described in nonhuman primates (Allman and Kass, 1971; Van Essen et al., 1984).

The PET techniques described and discussed above proved well suited to systematic, detailed mapping of primary visual cortex. Consistent topography, in accordance with the conventional scheme of retinotopy, was found in every instance. Delineation of cortical retinotopy in bicommissural coordinates has not, to our knowledge, been reported previously. However, the anatomical locations determined for each stimulus locale are in excellent agreement with the anatomical descriptions of Holmes and Lister (1916), as expressed in relation to the position of the inion, as well as with the numerous subsequent reports duplicating their findings. In addition, our response locales agree well with those predicted on the basis of the cortical magnification factor (see below). Also of interest is the observation that while macular responses often reached the occipital pole, they failed to extend onto the lateral surface of the occipital lobe, in agreement with earlier observations that only a small percentage, if any, of striate cortex extends beyond the medial wall of occipital cortex (Brindley, 1972; Stensaas et al., 1974; Braak, 1980).

The cortical magnification factor was calculated for 3 retinal eccentricities from the relation between response locale and mean stimulus eccentricity (Table 3 ). No compensation for cortical infolding or curvature of the calcarine fissure could be made, which tended to skew our values downward. Nevertheless, these estimates were within a factor of 2 (or less) of the values predicted in man by phosphene-locale mappings in 2 subjects (Cowey and Rolls, 1974; Dobelle et al., 1979) by extrapolating from the variations in ganglion cell density with retinal eccentricity 
(Rovamo and Virsu, 1979), and by homology with other primates (Daniel and Whitteridge, 1961).

In nonhuman primates, V2 is a duplicate retinotopic representation surrounding and in register with V1 (Zeki, 1969; Allman and Kass, 1971, 1974; Van Essen, 1985). The primary visual responses mapped herein certainly are predominantly striate, but probably also contain a significant V2 component. This suggestion is based on the following considerations: the greatest dorsal-ventral extent of human striate cortex (V1) is approximately $1 \mathrm{~cm}$ (Talairach et al., 1967; Stensaas et al., 1974). Yet our responses typically extended across 2-3 image planes $(1.4-2.8 \mathrm{~cm})$. While the exact size of the activated tissue could not be quantitated because of the limited spatial resolution of PET, the response span was consistent with a dorsal-ventral span of activated tissue exceeding $1 \mathrm{~cm}$. In addition, the separation between upper-field and lower-field response locales (1.4 $\mathrm{cm}$; Table 4) suggested that the detected responses were weighted by activated tissue lying outside $\mathrm{V} 1$, yet having very similar retinotopic topography, i.e., V2. While V1 and V2 were probably confounded when using annular stimuli, it may be possible to discriminate V2 from V1 in humans by comparing the response from a vertical-meridian visual stimulus with that from a horizontal-meridian stimulus. Whereas the vertical-meridians of V1 and V2 abut and should produce a single response focus, horizontal-meridian responses should be maximally separated.

Extrastriate responses. From our observations on these 7 subjects, it was clear that multiple, discrete extrastriate responses beyond V1/V2 were elicited by the relatively simple stimuli employed (Fig. 3). The number of distinct areas, their boundarics, their internal retinotopy or lack thereof, and possible functional specializations remain to be explored.

Localization versus resolution. The reader will note that activated brain areas were located with a precision surpassing the spatial resolution of the imaging system. Cortical zones separated by as little as $3 \mathrm{~mm}$ were distinguished using images with a resolution of $18 \mathrm{~mm}$ (FWHM). The solution of this apparent paradox resides in the distinction between resolution and localization. Localization refers to the precision with which the center of an isolated activity distribution can be measured. Simulations of focal brain activation using brain-phantom images indicate that our localization precision was less than $1 \mathrm{~mm}(\mathrm{M}$. A. Mintun, P. T. Fox, and M. E. Raichle, unpublished observations). Resolution is defined as the distance beneath which 2 simultaneously imaged activity distributions will be imaged as a single apparent focus, i.e., $18 \mathrm{~mm}$ for the images used here. We used paired-image subtractions to image activated brain areas as isolated foci of $\mathrm{rCBF} \Delta$, thereby capitalizing on the inherent precision of localization, rather than being limited to discriminations at the level of image resolution. This technique, in essence, is an application of the principle thought to underlie visual hyperacuity (Westheimer, 1979).

The success of this initial PET study of the organization of primary visual cortex demonstrates the feasibility of detailed neurophysiological experimentation in normal human subjects. Further explorations of the topography and functional specialization of human visual cortex, both primary and higher-order, are under way.

\section{References}

Allman, J. M., and J. H. Kaas (1971) Representation of the visual field in striate and adjoining cortex of the owl monkey, Aotus triviragatus. Brain Res. 35: 89-106.
Allman, J. M., and J. H. Kaas (1974) The organization of the second visual area (v-II) in the owl monkey: A second order transformation of the visual hemifield. Brain Res. 76: 247-265.

Allman, J. M., and E. R. McGuinness (1986) In Comparative Primate Biology, vol. 3, The Neurosciences, H. Steklis, ed., Alan R. Liss, New York.

Braak, H. (1980) Architectonics of the Human Telencephalic Cortex, pp. 64-70, Springer-Verlag, Berlin.

Brindley, G. S. (1972) The variability of human striate cortex. J. Physiol. (Lond.) 225: 1P-3P.

Brindley, G. S. (1973) Sensory effects of electrical stimulation of the visual and paravisual cortex in man. In Handbook of Sensory Physiology, vol. 7/3B, R. Jung, ed., pp. 583-594, Springer-Verlag, Berlin.

Brindley, G. S., and W. S. Lewin (1968) The sensations produced by electrical stimulation of the visual cortex. J. Physiol. (Lond.) 196: 479-493.

Brindley, G. S., P. E. K. Donaldson, M. A. Falconer, and D. N. Rushton (1972) The extent of the region of the occipital cortex that when stimulated gives phosphenes fixed in the visual field. J. Physiol. (Lond.) 225: 57P-58P.

Cowey, A., and E. T. Rolls (1974) Human cortical magnification factor and its relation to visual acuity. Exp. Brain Res. 21: 447-454.

Cupples, L. A., T. Heeren, A. Schatzkin, and T. Colton (1984) Multiple testing of hypotheses in comparing two groups. Ann. Int. Med. 100: 122-129.

Daniel, P. M., and D. Whitteridge (1961) The representation of the visual field on the cerebral cortex in monkeys. J. Physiol. (Lond.) 159: 203-221.

Dobelle, W. H., and M. G. Mladejovsky (1974) Phosphenes produced by electrical stimulation of human occipital cortex, and their application to the development of a prosthesis for the blind. J. Physiol. (Lond.) 243: 553-576.

Dobelle, W. H., J. Turkel, D. C. Henderson, and J. R. Evans (1979) Mapping the representation of the visual field by electrical stimulation of human visual cortex. Am. J. Ophthalmol. 88: 727-735.

Fox, P. T., and M. E. Raichle (1984) Stimulus rate dependence of regional cerebral blood flow in human striate cortex, demonstrated by positron emission tomography. J. Neurophysiol. 51: 1109-1120.

Fox, P. T., and M. E. Raichle (1985) Stimulus rate determines regional blood flow in striate cortex. Ann. Neurol. 17: 303-305.

Fox, P. T., and M. E. Raichle (1986) Focal physiological uncoupling of cerebral blood flow and oxidative metabolism during somatosensory stimulation in human subjects. Proc. Natl. Acad. Sci. USA 83: 1140-1144.

Fox, P. T., J. M. Fox, M. E. Raichle, and R. M. Burde (1985a) The role of cerebral cortex in the generation of voluntary saccades: A positron emission tomographic study. J. Neurophysiol. 54: 348-369.

Fox, P. T., J. S. Perlmutter, and M. E. Raichle (1985b) A stereotactic method of anatomical localization for positron emission tomography. J. Comput. Assist. Tomogr. 9: 141-153.

Fox, P. T., M. A. Mintun, M. E. Raichle, F. M. Miezin, J. M. Allman, and D. C. Van Essen (1986) Mapping human visual cortex with positron emission tomography. Nature 323: 806-809.

Herscovitch, P., J. Markham, and M. E. Raichle (1983) Brain blood flow measured with intravenous $\mathrm{H} 2150$. I. Theory and error analysis. J. Nucl. Med. 14: 782-789.

Holmes, G. (1918) Disturbances of vision by cerebral lesions. Br. J. Ophthalmol. 2: 353-384.

Holmes, G., and W. T. Lister (1916) Disturbances of vision in cerebral lesions with special reference to the cortical representation of the macula. Brain 39: 34-73.

McAuley, D. L., and R. W. Ross-Russell (1979) Correlation of CAT scan and visual field defects in vascular lesions of the posterior visual pathways. J. Neurol. Neurosurg. Psychiatry 42: 298-311.

Perlmutter, J. S., P. Herscovitch, W. P. Powers, P. T. Fox, and M. E. Raichle (1985) A standardized mean regional method for calculating global positron emission tomographic measurements. J. Cereb. Blood Flow Metab. 5: 476-480.

Raichle, M. E. (1983) Positron emission tomography. Annu. Rev. Neurosci. 6: 249-268.

Raichle, M. E., W. R. W. Martin, P. Herscovitch, M. A. Mintun, and J. Markham (1983) Brain blood flow measured with intravenous H2150. Implementation and validation. J. Nucl. Med. 24: 790-798.

Rovamo, J., and V. Virsu (1979) An estimation and application of the human cortical magnification factor. Exp. Brain Res. 37: 495510 . 
Sokoloff, L., R. Mangold, R. L. Wechsler, and S. S. Kety (1955) The effect of mental arithmetic on cerebral circulation and metabolism. J. Clin. Invest. 34: 1101-1108.

Spalding, J. M. D. (1952) Wounds of the visual pathway. II. The striate cortex. J. Neurol. Neurosurg. Psychiatry 15: 169-183.

Spector, R. H., J. S. Glaser, N. J. David, and D. Q. Viming (1981) Occipital lobe infarctions: Perimetry computed tomography. Neurology 31: 1098-1106.

Stensaas, S. S., D. K. Eddington, W. H. Dobelle (1974) The topography and variability of the primary visual cortex in man. J. Neurosurg. 40: 747-755.

Talairach, J., G. Szikla, P. Tournoux, A. Prosalentis, M. Bordas-Ferrier, L. Covello, M. Iacob, and E. Mempel (1967) Atlas d'Anatomie Stereotaxique du Telencephale, Masson, Paris.

Teuber, H., W. Battersby, M. Bender (1960) Visual Field Deficits After Penetrating Missile Wounds, Harvard U. P., Cambridge, MA.
Van Essen, D. C. (1985) Functional organization of primate visual cortex. In Cerebral Cortex, vol. 3, Visual Cortex, A. Peters and E. G. Jones, eds., pp. 259-329, Plenum, New York.

Van Essen, D. C., W. T. Newsome, and J. H. R. Maunsell (1984) The visual field representation in striate cortex of the macaque monkey: Asymmetries, anisotropies, and individual variability. Vision Res. 24: $429-448$

Westheimer, G. (1979) The spatial sense of the eye. Invest. Ophthalmol. Vis. Sci. 18: 893-912.

Yamamoto, M., D. C. Ficke, and M. M. Ter-Pogossian (1982) Performance study of PETT VI, a positron computed tomograph with 288 cesium fluoride detectors. IEEE Trans. Nucl. Sci. 29: 529-533.

Zar, J. H. (1974) Biostatistical Analysis, Prentice-Hall, Englewood Cliffs, NJ.

Zeki, S. M. (1969) Representation of central visual fields in prestriate cortex of monkey. Brain Res. 14: 271-291. 